\title{
Metacognitive and Control Strategies in Study-Time Allocation
}

\author{
Lisa K. Son and Janet Metcalfe \\ Columbia University
}

\begin{abstract}
This article investigates how people's metacognitive judgments influence subsequent studytime-allocation strategies. The authors present a comprehensive literature review indicating that people allocate more study time to judged-difficult than to judged-easy items-consistent with extant models of study-time allocation. However, typically, the materials were short, and participants had ample time for study. In contrast, in Experiment 1, when participants had insufficient time to study, they allocated more time to the judged-easy items than to the judged-difficult items, especially when expecting a test. In Experiment 2, when the materials were shorter, people allocated more study time to the judged-difficult materials. In Experiment 3, under high time pressure, people preferred studying judged-easy sonnets; under moderate time pressure, they showed no preference. These results provide new evidence against extant theories of study-time allocation.
\end{abstract}

The issue of how people use their metacognitive judgments about what they know and how well they know it to take control over their own learning is of primary concern in this article. The fact that in many situations people have relatively accurate metacognitions is well documented (Brown, 1978; Dunlosky \& Nelson, 1992, 1994, 1997; Gruneberg \& Monks, 1974; Jacoby, Bjork, \& Kelley, 1993; Johnson, 1988; Johnson \& Raye, 1981; King, Zechmeister, \& Shaughnessy, 1980; Koriat, 1975, 1993, 1995, 1997, 1998; Koriat \& Goldsmith, 1996, 1998; Leonesio \& Nelson, 1990; Lovelace, 1984; Mazzoni, Cornoldi, Tomat, \& Vecchi, 1997; Mazzoni \& Nelson, 1995; Metcalfe, 1986a, 1986b; Metcalfe, Schwartz, \& Joaquim, 1993; Metcalfe \& Weibe, 1987; Nelson, 1988; Nelson \& Dunlosky, 1991, 1992; Nelson, Leonesio, Landwehr, \& Narens, 1986; Schwartz \& Metcalfe, 1994; Schwartz \& Smith, 1997; Smith, Brown, \& Balfour, 1991; Thiede \& Dunlosky, 1994; Vesonder \& Voss, 1985; Widner \& Smith, 1996; Widner, Smith, \& Graziano, 1996). Ease-of-learning judgments (EOLs; Underwood, 1966), feeling-of-knowing judgments (FKJs; Hart, 1965; Nelson, Leonesio, Shimamura, Landwehr, \& Narens, 1982), and judgments of difficulty (JODs) or of learning (JOLs; Arbuckle \& Cuddy, 1969; Gardiner \& Klee, 1976; Groninger, 1979; King et al., 1980; Lovelace, 1984) generally have been shown to predict subsequent memory performance with above-chance accuracy. Having established that

Lisa K. Son and Janet Metcalfe, Department of Psychology, Columbia University.

This research was supported by National Institute of Mental Health Grant 48066. We would like to thank Ozlem Ayduk, Brady Butterfield, Rodolfo Mendoza-Denton, Jasia Pietrzak, and Lisa Schwartz for their help. We also appreciate the comments of Thomas $\mathrm{O}$. Nelson, Keith Thiede, and an anonymous reviewer on a draft of this article.

Correspondence concerning this article should be addressed to Lisa K. Son, Department of Psychology, 406 Schermerhorn Hall, Columbia University, New York, New York 10027. Electronic mail may be sent to son@psych.columbia.edu. people appear to have access to accurate metaknowledge, the question of how they put that knowledge to use is becoming focal.

Some theories indicate that metacognitions play a central role in a variety of cognitive tasks, including memory retrieval (Reder, 1987; Reder \& Ritter, 1992), initial memory encoding (Metcalfe, 1993), problem solving (Metcalfe, 1986b; Simon \& Newell, 1971), and self-directed learning (Nelson \& Narens, 1994). As was assumed by early researchers such as Flavell (1979) and Flavell and Wellman (1977), these self-reflective processes are crucial in controlling and guiding human cognition (see Metcalfe, 1996, in press, for review). Recently, investigators have begun intensively and systematically to explore the question of primary interest in this article: How do people use these metacognitive judgments to control their study-time allocation and hence to determine what it is that they will learn?

Interest in the control functions of people's metacognitions was fostered by a framework for human metacognition forwarded by Nelson and Narens $(1990,1994)$, who suggested that the human cognitive system has (at least) two interacting levels-a basic level and a metalevel. The latter monitors and contains a model of the former and, importantly, for purposes of the present article, controls the learning that goes on at the basic level. Although they did not propose a detailed model of exactly how the control processes functioned, Nelson and Narens's (1994) framework has nevertheless been crucial in allowing others to do so.

Dunlosky and Hertzog (1998) provided a more formal formulation-a discrepancy-reduction model - that focused directly on the detailed mechanisms of metacognitive control of study time. This model is divided into three main stages. The first is study preparation, including processes related to memory self-efficacy evaluation, task appraisal, and initial strategy selection. Task appraisal and initial strategy selection, in their model, are informed by metacognitive knowledge but not by fine-grained assessments of the learning of the materials at hand. The second stage, that of on-going study, includes the selection of individual items 
and the monitoring of learning of those items. Once the item has been studied, its learning state is monitored and a decision is made about whether the item has achieved the desired degree of learning. If it has, then study of that item is terminated, the model goes on to the third phase (which involves testing), and the whole loop starts again. If the item has not met the desired degree of learning, though, it is sent back for more study. The second stage of this modelwherein items are studied until they are perceived to have been learned-is most relevant to the experiments that we present in the present article.

Dunlosky and Hertzog (1998) described this central discrepancy-reduction characteristic of the model as follows:

During on-going study, a person may monitor how well an individual item has been learned. This perceived degree of learning may then be compared to the degree of learning the person desires for the item, which is called the norm of study. If the perceived degree of learning is less than the norm of study, the person presumably will continue to study the item or will select a new study strategy to use. If the perceived degree of learning meets or exceeds this norm of study, the person will terminate study of that item and proceed to another. One implication of this discrepancy-reduction mechanism of self-paced study is that a person's perceived degree of learning will be inversely related to subsequent study time. (pp. 252-253)

Although Dunlosky and Hertzog's presentation is especially informative in being given as a flow chart with the individual processes being relatively well defined, other researchers have honed in on the same basic conclusion-that people allocate their study time to the items that are perceived to be the most difficult (e.g., Nelson \& Narens, 1994).

One caveat to this general view comes from a recent study by Thiede and Dunlosky (1999). One might expect that if people study the most difficult items longer, they will also study them first. However, Thiede and Dunlosky found evidence to the contrary: People sometimes choose to study the easier items first, rather than choosing the difficult items first. This finding could be taken as evidence that there may be some conditions under which the most difficult items do not take priority. Alternatively, this item choice could be attributed to the first phase of study in which a strategy is selected in the Dunlosky and Hertzog (1998) model. And, indeed, Thiede and Dunlosky (1999) proposed a model in which there is a higher order strategy-selection stage that includes choosing which items to study. That done, the discrepancy-reduction mechanism is assumed to apply to all items so chosen. Thus, so long as the data are conditionalized on those items that were selected at all, this modified model predicts that study time should be negatively correlated with perceived item difficulty. As might be expected from the undisputed theoretical dominance of the idea that people study the difficult items longer to reduce the discrepancy between their perceived learning and their desired learning, this (until now) unchallenged view has received considerable empirical support.

A number of investigators have used a particular paradigm for studying the relation between metacognitive JOLs and study-time allocation. Typically, participants first rate the ease of learning particular items and thereafter have time to study each item individually, for as long as they wish, for a later memory test. In this paradigm, people have tended to study the judged-difficult-to-learn materials longer than they studied the judged-easy-to-learn materials (Cull \& Zechmeister, 1994; Mazzoni \& Cornoldi, 1993, Experiments 1, 4, 5; Mazzoni, Cornoldi, \& Marchitelli, 1990, Experiments 2, 3; Nelson, Dunlosky, Graf, \& Narens, 1994; Nelson \& Leonesio, 1988; Thiede \& Dunlosky, 1999). Presumably, the reason for this finding is that it takes more time for people to master the materials that are difficult or are judged-to-bedifficult than it does to master the easy materials, and, hence-on the assumption that the goal is mastery-people must and do spend more time studying the difficult materials.

This result has been found not only with normal college students but in other populations as well, for example, with children (Dufresne \& Kobasigawa, 1988, 1989; Kobasigawa \& Dufresne, 1992, cited in Kobasigawa \& Metcalf-Haggert, 1993; Nelson et al., 1994) and with older adults (Dunlosky \& Connor, 1997; Dunlosky \& Hertzog, 1997). Several studies did not assess people's metacognitions but rather examined the effects of objective item difficulty on studytime allocation (Belmont \& Butterfield, 1971; Bisanz, Vesonder, \& Voss, 1978; Dufresne \& Kobasigawa, 1988, 1989; Kellas \& Butterfield, 1971; Kobasigawa \& Dufresne, 1992; Kobasigawa \& Metcalf-Haggert, 1993; Le Ny, Denhiere, \& Le Taillanter, 1972; Masur, McIntyre, \& Flavell, 1973; Zacks, 1969), but the results were, nevertheless, similar; that is, people devoted more study time to the difficult items.

The few exceptions to this rule come from investigations with young children, but even these often show preferential allocation of study time to the judged-difficult items. In Dufresne and Kobasigawa's (1989) study, children in Grades $1,3,5$, and 7 were asked to study two booklets of paired associates until they could remember all of the pairs perfectly. For each child, one booklet was easy, and the other was difficult. The difficulty was determined by the relatedness or unrelatedness of the paired associates. Although the children in Grades 1 and 3 spent approximately equal amounts of time on the easy and difficult booklets, the older children in Grades 5 and 7 spent more time studying the difficult booklet. The authors suggested that the younger children did not realize that the more difficult materials either were more difficult or might require more intensive effort. In a related study, Kobasigawa and Metcalf-Haggert (1993) found that when the materials were pictures of familiar objects rather than verbal paired associates, as had been used in the Dufresne and Kobasigawa (1989) study, even first graders allocated more study time to materials that were more difficult. The discrepancy in the findings might be attributable to the fact that studying pictures makes more sense to elementary school children than studying unrelated paired associates, and so metacognitive strategies were more likely to come into play.

The literature on study-time allocation converges on the conclusion that people tend to allocate their study time to items they judge to be difficult. In Table 1 , we provide a comprehensive review of the extant experimental literature on the relation between difficulty and study time. We were 
Table 1

A Review of the Literature on Metacognitive Control in Study-Time Allocation

\begin{tabular}{|c|c|c|c|c|}
\hline Experimenter & Particpants & Materials & $\begin{array}{l}\text { Determinant } \\
\text { of difficulty" }\end{array}$ & $\begin{array}{l}\text { Allocated } \\
\text { study } \\
\text { time to }\end{array}$ \\
\hline \multicolumn{5}{|c|}{ Previous studies } \\
\hline Belmont \& Butterfield, 1971 & Normal teenagers & Letters & Serial position & Difficult \\
\hline & Mildly retarded teenagers & Letters & & \\
\hline \multirow[t]{3}{*}{ Bisanz, Vesonder, \& Voss, 1978} & 1st graders & Cue-target pairs & Recalled vs. unrecalled pairs & Null \\
\hline & $\begin{array}{l}\text { 3ro graders } \\
\text { 5th graders }\end{array}$ & $\begin{array}{l}\text { Cue-target parrs } \\
\text { Cue-target pairs }\end{array}$ & & $\begin{array}{l}\text { Dincult } \\
\text { Difficult }\end{array}$ \\
\hline & College students & Cue-target pairs & & Difificult \\
\hline Cull \& Zechmeister, 1994, Exp. 1 & Adults & Cue-target pairs & Learned vs. unlearned pairs & Difficult \\
\hline Cull \& Zechmeister, 1994, Exp. 2 & Adults & Cue-target pairs & Learned vs. unleamed pairs & Difificult \\
\hline Dufresne \& Kobasigawa, 1988 & 1st graders & Cue-target pairs & Related vs. unrelated & Null \\
\hline & 3rd graders & Cue-target pairs & & Null \\
\hline \multirow[t]{4}{*}{ Dufresne \& Kobasigawa, 1989} & 1st graders & Cue-target pairs & Related vs. unrelated & Null \\
\hline & 3rd graders & Cue-target pairs & & Null \\
\hline & 5th graders & Cue-target pairs & & Difficult \\
\hline & 7th graders & Cue-target pairs & & Difficult \\
\hline Dunlosky \& Connor, 1997, Exp. 1 & Adults, aging adults & Cue-target pairs & JOLs & Difiricult \\
\hline Dunlosky \& Connor, 1997, Exp. 2 & Adults, aging adults & Cue-target pairs & & Difficult \\
\hline Dunlosky \& Hertzog, 1997 & Adults & Cue-target pairs & JOLs & Difficult \\
\hline \multirow{3}{*}{ Kellas \& Butterfield, 1971} & $\begin{array}{l}\text { Aging adults } \\
\text { Adults }\end{array}$ & Cue-target pairs & Serial moition & Difficult \\
\hline & Adults & Bigrams & Serial position & Difficult \\
\hline & Adults & Trigrams & & Difficult \\
\hline \multirow[t]{4}{*}{ Kobasigawa \& Dufresne, 1992} & 1st graders & Cue-target pairs & Related vs. unrelated & Null \\
\hline & 3rd graders & Cue-target pairs & & Difficult \\
\hline & 5th graders & Cue-target pairs & & Difficult \\
\hline & 7th graders & Cue-target pairs & & Difficult \\
\hline Kobasigawa \& Metcalf-Haggert, & 1st graders & Objects & Familiar vs. unfamiliar & Difficult \\
\hline 1993 & 3rd graders & Objects & & Difficult \\
\hline $\begin{array}{l}\text { Le Ny, Denhiere, \& Le Taillanter, } \\
1972\end{array}$ & Adults & Cue-target pairs & Recalled vs. unrecalled items & Difficult \\
\hline \multirow[t]{2}{*}{ Masur, McIntyre, \& Flavell, 1973} & 1st graders & Object drawings & Recalled vs. unrecalled items & Null \\
\hline & 3rd graders & Object drawings & & Difficalt \\
\hline Mazzoni \& Cornoldi, 1993, Exp. 1 & $\begin{array}{l}\text { Adults } \\
\text { Adults }\end{array}$ & Object drawings & IOLs & Dithcult \\
\hline Mazzoni \& Cornoldi, 1993, Exp. 4 & $\begin{array}{l}\text { Aucus } \\
\text { Adults }\end{array}$ & Iransiuve sentences & JOLs & $\begin{array}{ll}\text { Dimincult } \\
\text { Diffenlt }\end{array}$ \\
\hline Mazzoni \& Cornoldi, 1993, Exp. 5 & Adults & Informational sentences & JOLs & Nulle \\
\hline $\begin{array}{l}\text { Mazzoni, Cornoldi, \& Marchitelli, } \\
\text { 1990, Exp. } 1\end{array}$ & Adults & Nouns & JOLs & Nulle \\
\hline Mazzoni et al., 1990 , Exp. 2 & Adults & Nouns & JOLs & Difficult \\
\hline Mazzoni et al., 1990, Exp. 3 & Adults & Transitive sentences & JOLs & Nulle \\
\hline $\begin{array}{l}\text { Mazzoni, Cornoldi, Tomat, \& } \\
\text { Vecchi, 1997, Exp. } 2\end{array}$ & Adults & Food items & $\begin{array}{l}\text { Typicality of item and fre- } \\
\text { quency of purchase }\end{array}$ & Difficult \\
\hline Mazzoni et al., 1997, Exp. 3 & Adults & Food items & & Difficult \\
\hline \multirow{6}{*}{$\begin{array}{l}\text { Nelson, Dunlosky, Graf, \& } \\
\text { Nairens, } 1994 \\
\text { Nelson \& Leonesio, 1988, Exp. } 1 \\
\text { Nelson \& Leonesio, 1988, Exp. } 2 \\
\text { Nelson \& Leonesio, 1988, Exp. } 3 \\
\text { Thiede \& Dunlosky, } 1999 \\
\text { Zacks, } 1969\end{array}$} & Adults & Cue-target pairs & JOLs & Difficult \\
\hline & Adults & Trigrams & EOLs & Difficult \\
\hline & Adults & Word-trigram pairs & EOLs, FKJs & Difficult \\
\hline & Adults & General questions & FKJs & Difficult \\
\hline & Adults & Cue-target pairs & JOLs & Difficult \\
\hline & Adults & Cue-target pairs & Recalled vs. unrecalled items & Difficult \\
\hline \multirow{5}{*}{$\begin{array}{l}\text { Son \& Metcalfe, present article, } \\
\text { Exp. } 1 \\
\text { Son \& Metcalfe, present article, } \\
\text { Exp. } 2 \\
\text { Son \& Metcalfe, present article, } \\
\text { Exp. } 3\end{array}$} & $\mathrm{Cu}$ & nt studies & & \\
\hline & Adults & Long biographies & EOLs & Easy \\
\hline & Adults & Short haikus & EOLs & Difficult \\
\hline & & & & \\
\hline & Adults & Medium sonnets & EOLs & Easy \\
\hline
\end{tabular}

This column indicates how the materials were classified as being easy or difficult. In most cases, participants gave metacognitive judgments of learning. However, in other cases, objective item difficulty, such as the relatedness or unrelatedness of a cue-target pair, was used. bDifficult indicates that participants allocated more study time to difficult materials, null indicates that there was no systematic allocation of study time, and easy indicates that they allocated more time to the easier materials. COnly raw study times were reported, showing that, on average, people spent more time studying items that were intermediate in difficulty. 
able to find 19 published reports in total, which together contain 46 treatment combinations. For each of the studies provided in Table 1, we include a description of the materials used, the participants, and the way in which difficulty was assessed. Of these 46 published conditions, 35 showed that people exhibited a clear preference for studying the more difficult materials. Three conditions showed that extra time was allocated to items of intermediate difficulty (Mazzoni \& Cornoldi, 1993; Mazzoni, Cornoldi, \& Marchitelli, 1990). Eight conditions showed that participants did not spend more time on either the easy or the difficult items or that the results were nonsignificant. These null results include data from the first graders and from mildly retarded teenagers who might have had a problem assessing difficulty. There were no studies showing a tendency to allocate more study time to easy materials.

These results, of course, indicate that people behave in a highly strategic manner, as Nelson and Narens (1994) have suggested. The particular strategy that they seem to be using appears to be the one proposed by the discrepancy-reduction models (Dunlosky \& Hertzog, 1998; Thiede \& Dunlosky, 1999). These results seem definitive.

Although the extant theories and data seem overwhelmingly to favor the hypothesis that people preferentially allocate their study time to the difficult items, we suggest that that conclusion may be premature. The results of the above-cited experiments may instead be attributable to the very specific experimental materials and conditions used. For example, in nearly all of these experiments, the goal of learning was complete verbatim recall. Although there are many situations in which verbatim recall is essential-as in learning nouns or short phrases in language learning-there may be just as many situations in which verbatim mastery is not the goal, and may even be impossible-as in understanding the facts of a large text. Thus, short materials such as word-pairs, which the participant is required to recall perfectly, might give rise to entirely different study strategies than would more complex materials such as long texts and stories from which the person is expected to extract the essential points.

In past studies, participants were nearly always allowed ample time to study all of the items- - one by one-until they were sure that they could remember them all. In many real-world learning situations, however, time pressures exist, forcing people to choose which materials to study, realizing that some of the material may not get learned. Under these circumstances, their strategies might change.

Finally, people may not be guided purely by their assessments of the difficulty of the events. Other factors entirely, such as a person's interest or motivation, may drive study-time allocation. It has been shown in a number of studies that people demonstrated better learning of judgedinteresting information than of judged-uninteresting information (Asher, 1979; Asher, Hymel, \& Wigfield, 1978; Asher \& Markell, 1974). As a result of the findings, Asher (1980) tested a selective-attention hypothesis, which says that the learning of interesting information was enhanced because extra time or attention was allocated to the interesting information, and the attention improved learning. His statis- tical analysis, though, failed to support the causal role of the attention. Furthermore, Anderson (1982) also found that increased attention to an interesting topic was not causal in learning. Fourth graders were given sentences to read that had been rated for interest by a group of third graders. Reading times and probe times were collected before taking a free-recall test. Results showed that the interest values had significant relations to recall, reading time, and probe time. However, reading time did not have a significant positive relation to recall. Similarly, Shirey and Reynolds (1988) conducted a study that investigated the effects of interest judgments on both attention and learning. After rating sentences for interest, participants were given reading time or time in which to allocate attention to the sentences selectively. A cued-recall test showed that although the interesting sentences were learned better, less attention had been allocated to them, suggesting that attention did not serve as a causal mediator between interest and learning. Given the importance of the relation between interest and study time, we undertook to explore the role of interest, as well as that of difficulty, in study-time allocation.

To begin our investigation of the role of interest, difficulty, and other potential variables, we began by asking 33 Columbia University students "How do you allocate your study time?" They were asked to write down as much as they wanted for as long as they wanted to answer the question, giving multiple answers if they desired. Consistent with past experimental findings, 12 students said that they spent most of their time studying difficult topics. However, 11 said they spent their time studying interesting topics, and 2 said they spent their time studying important topics. Finally, 13 students indicated that their strategy depended on whether or not a test was approaching. If they were expecting a test soon, they spent more time studying the material that was to be tested. These results, as well as our own intuitions, suggested that the seemingly robust conclusion of past experimental research and theory, that people, virtually without exception, allocate their study time to the difficult items, might be too simple and warranted reexamination.

In contrast to the tenets of discrepancy-reduction theories, then, it seems plausible to suppose that there may be conditions under which people would reasonably preferentially allocate study time to items other than those that are difficult. For example, items that are judged as too difficult to learn given the temporal constraints of a particular situation might best be left unstudied. In such cases, allocating more study time to extremely difficult materials might be a waste of time and might also needlessly divert the person's efforts from easier items that could benefit from additional study. Atkinson (1972), in an important but neglected classic article, proposed a three-stage Markov model of an optimal control strategy in which the most study time is allocated to items that are in an intermediate state of learning - not fully learned but also not totally unlearned. In his investigation, the allocation of study time to items that were neither too difficult nor too easy was found to be the most effective strategy. Thus, there should be situations in which people would be better off not allocating study time as 
a direct function of judged difficulty but might, instead, benefit from allocating extra time to other items, such as moderately difficult items (e.g., Mazzoni \& Cornoldi, 1993; Mazzoni et al., 1990). Furthermore, the amount of time allowed to the student may be crucial in determining a reasonable study-time-allocation strategy.

In three experiments, we attempted to answer several fundamental questions dealing with metacognitive control strategies in a study-time-allocation paradigm. First, what are the conditions under which people allocate more study time to materials that they judge to be difficult, and when might they devote study time to judged-easy items? Second, how do test expectations influence study-time allocation? Finally, how might a person's interest in the material influence study-time allocation?

\section{Experiment 1}

In Experiment 1, we manipulated the goals or test expectations of the participants by varying the instructions about whether they would be tested on the materials. One group of participants-the study-for-test group-expected to be tested on the to-be-learned biographies, whereas another group-the free-reading group-did not expect to be tested. There is a large literature suggesting that a person's goals can influence their subsequent behavior (e.g., Dweck, 1996; Gollwitzer \& Moskowitz, 1996; Grant \& Dweck, 1999; Thiede, 1996). However, the cognitive literature on test expectations and intention to learn is mixed. Several experiments have shown differences in performance as a function of whether or not the person knows that he or she will be tested (Kausler, Laughlin, \& Trapp, 1963; Kausler \& Trapp, 1962; McDaniel, Blischak, \& Challis, 1994). For example, McDaniel et al. (1994) found that people who were expecting a test were more apt to identify and focus on the important information in a text passageand, as a consequence, perform better-than those who were not expecting a test. Other studies, though, have shown no performance differences (Hyde, 1973; Hyde \& Jenkins, 1969, 1973; Johnston \& Jenkins, 1971; Wolk, 1974). A number of theorists have suggested that the mere intention to learn, itself, does not influence memory; rather, differences result because the participants use different cognitive operations or strategies (Craik \& Tulving, 1975; Craik \& Watkins, 1973; Hyde, 1973; Hyde \& Jenkins, 1969, 1973; Postman, 1964; Till \& Jenkins, 1973; Walsh \& Jenkins, 1973). The primary interest in this experiment was in understanding how people vary their strategies during study. Thus, we were not investigating whether mere intention to learn alters learning but rather whether test expectations alter people's strategies, as given by the correspondence between their metacognitive judgments and their study-time allocation.

We also considered that metacognitions other than EOLs might predict people's study-time allocation, maybe especially when they were not expecting to be tested. Perhaps when people are reading for pleasure, their time-allocation strategies are different than when they are studying for a test. It may be that only in the latter case do they focus their efforts on the most difficult materials, as past research has shown. When people are reading for pleasure, they might be guided more by their interest. Accordingly, two metacognitive judgments-EOLs and JOIs were investigated. We thought it likely that when people were not expecting a test; they would allocate study time to the items they thought were interesting, whereas when they expected to be tested, they would study the items they believed would optimize test performance.

We also chose to use biographies rather than paired associates as the to-be-leamed materials. There were several reasons for choosing biographies. First, we wanted to use the kinds of longer materials a person might encounter in a classroom situation, such as complicated texts. We also wanted the materials to be long enough so that people would not have enough time to study all the materials completely and, consequently, would need to make time-allocation decisions. Finally, we wanted materials that might have some intrinsic interest to participants so we could examine how JOIs related to study-time allocation. We thought that participants would show more variation of interest for biographies than for the more homogenous (and monotonous) materials used in previous studies-making assessment of interest both a plausible task and one that might allow us to see variations in study strategies.

Finally, we wanted to create a situation in which the participants would behave strategically. In all previous studies, except for that of Thiede and Dunlosky (1999), participants were shown the individual to-be-learned items one by one and in an order determined by the experimenter and were allowed to spend a variable amount of time on each item. Under such circumstances, it would usually be advantageous to the person's eventual performance to continue studying each item until it was believed to be learned. Not surprisingly, then, participants would spend more time on the more difficult items-the normative finding. However, this is not the situation typically faced by a student under time pressure to learn an entire set of materials. Decisions need to be made about how to best spend the limited amount of time available. We postulated that under these more realistic conditions, the usual finding of attention to the most difficult items might not hold and that people might try to optimize their time in a different, but as yet unknown, manner. Therefore, we modified the standard paradigm to allow the participant to freely choose whichever items he or she wanted to study within the constraint of a total fixed amount of time and investigated their choices among items within that total time.

\section{Method}

\section{Participants}

The participants were 64 Columbia University undergraduates. Half were recruited during one term and the other half during a different term from introductory psychology classes at Columbia University. The students received some course credit for their participation. One participant was eliminated from the analyses because he did not follow directions, leaving an $n$ of 63 . 


\section{Design}

The main between-participants manipulation was test expectation (study-for-test vs. free-reading). Participants were asked to study eight different biographies and were subsequently given 64 fill-in-the-blank questions, 8 testing each of the biographies. We collapsed over test questions to give proportion correct for each biography. Participants made two kinds of metacognitive judgments-EOL and JOI $\longrightarrow$ on each of the eight to-be-learned biographies. The EOLs were made on the cue of only one paragraph of a multiparagraph biography. (In most other experiments, the EOLs were made on the cue of the entire to-be-learned item). In the first semester, when 32 participants were tested, the order of judgment was balanced across participants so that half of the participants gave EOLs first, and the other half reported their JOIs first. This process made no difference in any results, so in the following semester when the additional 31 participants were run, all of them gave EOLs first and JOIs second, and this control factor was ignored in the analyses. In addition to recall test performance, we measured study time on each biography and the number of pages studied. Participants were tested individually and assigned randomly to test expectation and judgment order.

\section{Procedure}

The experiment consisted of three stages. First, the participants were asked to read one-paragraph biographical introductions for the eight different famous figures and to rank them in terms of EOL and JOI (judgment stage). Second, all participants were allowed to read and study the complete six-page biographies for as long as they wished on each, and in any order they chose, for $30 \mathrm{~min}$ (study stage). Finally, the participants were given a fill-in-the-blank test (recall stage). Each stage is described in more detail below.

Judgment stage. Participants read a short paragraph from each of the eight biographies. They were asked to order these in terms of their EOL (coded from $1=$ most difficult to $8=e a s i e s t$ ) and JOI (coded from $1=$ least interesting to $8=$ most interesting). They were given as much time as they needed to complete this task.

After having made their judgments, but before beginning the second stage of the experiment, participants in the study-for-test condition were told that they would be tested on the material from all eight biographies; participants in the free-reading condition were told nothing about a test. The instructions for the study-fortest condition were as follows: "You will now have the opportunity to read through and study the full biographies for $30 \mathrm{~min}$. There will be a memory test given after the 30 minutes has ended, and it will be testing material from all 8 biographies. You may read the biographies as you wish, choosing each of them for as long as you like. You can always go back to one that you've already read, and don't worry if you don't get through all of them." The instructions for the free-reading condition were as follows: "You will now have the opportunity to free-read through the full biographies for $30 \mathrm{~min}$. You may read the biographies as you wish, choosing each of them for as long as you'd like. You can always go back to one that you've already read, and don't worry if you don't get through all of them."

Study stage. After hearing the instructions, participants in both the study-for-test and free-reading groups had the opportunity to read the complete biographies for $30 \mathrm{~min}$. The names of the biographies were presented in a circular array on the computer screen. Participants chose which six-page biography they wished to study by pressing in a letter key that corresponded to that biography. At any time, the participant could return to the main array to choose a different biography by pressing the space bar. The total study time was $30 \mathrm{~min}$, but it could be allocated as the participant chose. The time spent on each biography, the number of pages read, and the order in which the biographies were read were all recorded by computer.

Recall stage. The participants received a 64-question, fill-inthe-blank test consisting of eight questions from each biography. The questions were presented randomly on the computer screen for $15 \mathrm{~s}$ each. All participants were told that they should answer the questions as quickly as possible by typing in the answer. If they could not answer the question within $15 \mathrm{~s}$, the computer automatically moved on to the next question. The participants' answers were saved on a computer file to be hand scored later. There were two independent scorers, both blind to the experimental conditions. Each correct fill-in-the-blank answer was given a point, and each incorrect answer was given no points. There were no partial points given. Spelling mistakes were counted as correct. The two scorers produced exactly the same total score for each of the participants.

\section{Materials}

The biographies were chosen from each of eight different categories consisting of art, psychology, sports, literature, science, philosophy, political history, and classical music. The figures were Pablo Picasso, Sigmund Freud, Babe Ruth, William Shakespeare, Isaac Newton, Aristotle, George Washington, and Johann Sebastian Bach. The biographies were taken from the Encyclopedia Britannica and were organized so that all were exactly six computerscreen pages long and consisted of similar information.

\section{Pretesting of Biographies}

We wanted participants to be time pressured while reading the biographies. Therefore, before conducting the experiment, two graduate students read through all eight biographies continuously while being timed. This took $55 \mathrm{~min}$ for one and $60 \mathrm{~min}$ for the other, nearly twice as long as we allowed participants in the experiment.

The biographies were also pretested to ensure that they were about people who were relatively similar in fame. Twenty-one participants (who were not participants in the experiment proper) were asked to list three of the most famous, nonliving people for each of the following categories: art, politics, English literature, science, philosophy, psychology, sports, and classical music. All of the biographies chosen for the experiment were among the most commonly listed names in the survey. Picasso was the most commonly listed name under the category art (10); Washington in politics (15); Shakespeare in literature (13); Freud in psychology (16); Babe Ruth in sports (17); Newton (11) came in second in the science category after Einstein; Aristotle (8) came in second in the philosophy category after Plato; and Bach (11) came in third in the music category after Beethoven and Mozart.

\section{Results}

In all of the analyses, a probability level of .05 was used as the criterion for statistical significance. We computed all correlations nonparametrically (using gammas, $G-a$ rankorder correlation on two dimensions; see Nelson, 1984) and parametrically (using Pearson product-moment correlations, $r$ ). Because both types of correlations nearly always gave the same basic results, we report only gamma correlations, except when the two showed different patterns, in which case we report both. 


\section{Test Performance}

The mean proportion correct on the test for the freereading and study-for-test groups were .20 and .23 , respectively. Though these means were in the right direction for the hypothesis that studying for a test improves test performance, the difference failed to reach statistical significance, $F(1,61)=1.36, M S E=0.08, p=.25$. This lack of difference suggested that despite our earlier survey in which participants had indicated that their study behavior seemed to depend on whether a test was expected, such an expectation had, at best, a small impact on test performance-at least in the present experiment. There was a difference in recall depending on biography, $F(7,427)=28.98, M S E=$ 0.78 , such that people tended to recall more facts about certain biographies, such as Picasso, over others, such as Newton.

The gamma correlations between judgments and test performance are presented in Table 2 (Experiment 1). The mean gamma correlations between EOLs and test performance were .19 and .21 for the free-reading and study-fortest conditions, respectively. Although there were no significant differences as a function of test expectation $(F \mathrm{~s}<1)$, the correlations were significantly greater than zero, indicating that people performed better on the biographies that were judged to be easy, $t(62)=6.03, S E=0.03$. They also performed better on biographies that were judged to be interesting, $t(62)=5.84, S E=0.03$.

As study time increased, so, too, did test performance; the gamma $(G=26)$ was significantly greater than zero, $t(62)=8.86, S E=0.03$. Similarly, when the number of pages read on each biography was correlated with test performance, the relation was also significantly positive, $G=.26, t(62)=9.69, S E=0.03$.

\section{Cognitive Resource Allocation on the Basis of EOLs}

In this analysis, the data were the measured study time for each of the eight biographies as related to the person's EOL on each biography. If a certain biography had not been

Table 2

The Relation Between Metacognitive Judgments and Test Performance (Gamma Correlations")

\begin{tabular}{ccc}
\hline Group & $\begin{array}{c}\text { Ease-of-learming } \\
\text { judgment }\end{array}$ & $\begin{array}{c}\text { Judgment } \\
\text { of interest }\end{array}$ \\
\hline Experiment 1 & .19 & .23 \\
$\quad$ Free reading & .21 & .18 \\
$\begin{array}{c}\text { Study for test } \\
\text { Experiment 2 }\end{array}$ & .26 & .12 \\
$\begin{array}{c}\text { Free reading } \\
\text { Study for test }\end{array}$ & .24 & .07 \\
Experiment 3b & .19 & .08 \\
Moderate pressure & .22 & .17 \\
\hline High pressure & .22 & \\
\hline
\end{tabular}

A negative gamma correlation indicates that people performed better on the judged-difficult or judged-boring biographies, and a positive correlation indicates that people performed better on the judged-easy or judged-interesting biographies. bAll participants expected a test in Experiment 3. studied at all, it had a study time duration of zero. In contrast to previous findings in the literature, people allocated more study time to items they judged as easy, rather than to those that they judged difficult. The gamma $(G=.19)$ was significantly greater than zero, $t(62)=4.68, S E=0.04$, and is shown in Figure 1. This is a reversal of the usual finding.

The mean gamma correlations between EOLs and study time for the free-reading group (.27) and study-for-test group $(.10)$ were significantly different from one another, $F(1,62)=5.05, M S E=0.47$, indicating that participants' knowledge that they were going to face a test affected their strategies in studying. When they were studying for a test, they had less of a tendency to allocate study time to the judged-easy biographies than when they were free reading, and only the free-reading group had a mean gamma that was significantly different from zero, $t(30)=5.80, S E=0.05$.

Thiede and Dunlosky's (1999) theory suggests that people might strategically allocate study time to the most difficult items only after the particular item has been selected for study. They found that people sometimes chose to study the easier items early. In the present experiment, we also found that people tended to choose the easier items early, especially when free reading. The mean gamma correlation between EOLs and order of study for the free-reading group was $-.27, t(31)=3.97, S E=0.07$. For the study-for-test group, the gamma was -.01 , which was not different from zero. The two groups were significantly different from each other, $t(31)=2.24, S E=0.20$. (When the correlations were computed parametrically, though, this difference between groups disappeared. The $r$ correlation for the free-reading group was -.29 and for the study-for-test group was -.15 , both showing that people studied the judged-easy items early.) Thus (although the conclusion may not be entirely firm for the study-for-test group), these data on order of selection appear to confirm Thiede and Dunlosky's order of study results.

Given that people did choose the easier items first and did not have time to get through all of the to-be-tested materials, it is possible that the reversal of the usual finding on time allocation that we reported above might have been attributable to people rarely having selected the judged-difficult items at all. Thus, it is possible that, as Thiede and Dunlosky (1999) and Dunlosky and Hertzog (1998) proposed, the discrepancy-reduction mechanism was operating on the materials that people selected for study, but they selected only the easy items, so the overall correlations show a reversal that does not contradict the models.

To test this theory, it is necessary to conditionalize the data, eliminating those items that were not selected at all for study. A second analysis was, therefore, conducted in which the data were conditionalized on only those biographies that were chosen for study. The final item each participant selected was also removed because study of that item would most likely have been cut off by the 30-min study-time limit. Hence, the person may not have devoted as much time to that item as he or she would have wished. Thus, in the second analysis, only those biographies that participants chose to study and were free to finish studying were used. The mean number of biographies contributing to the condi- 


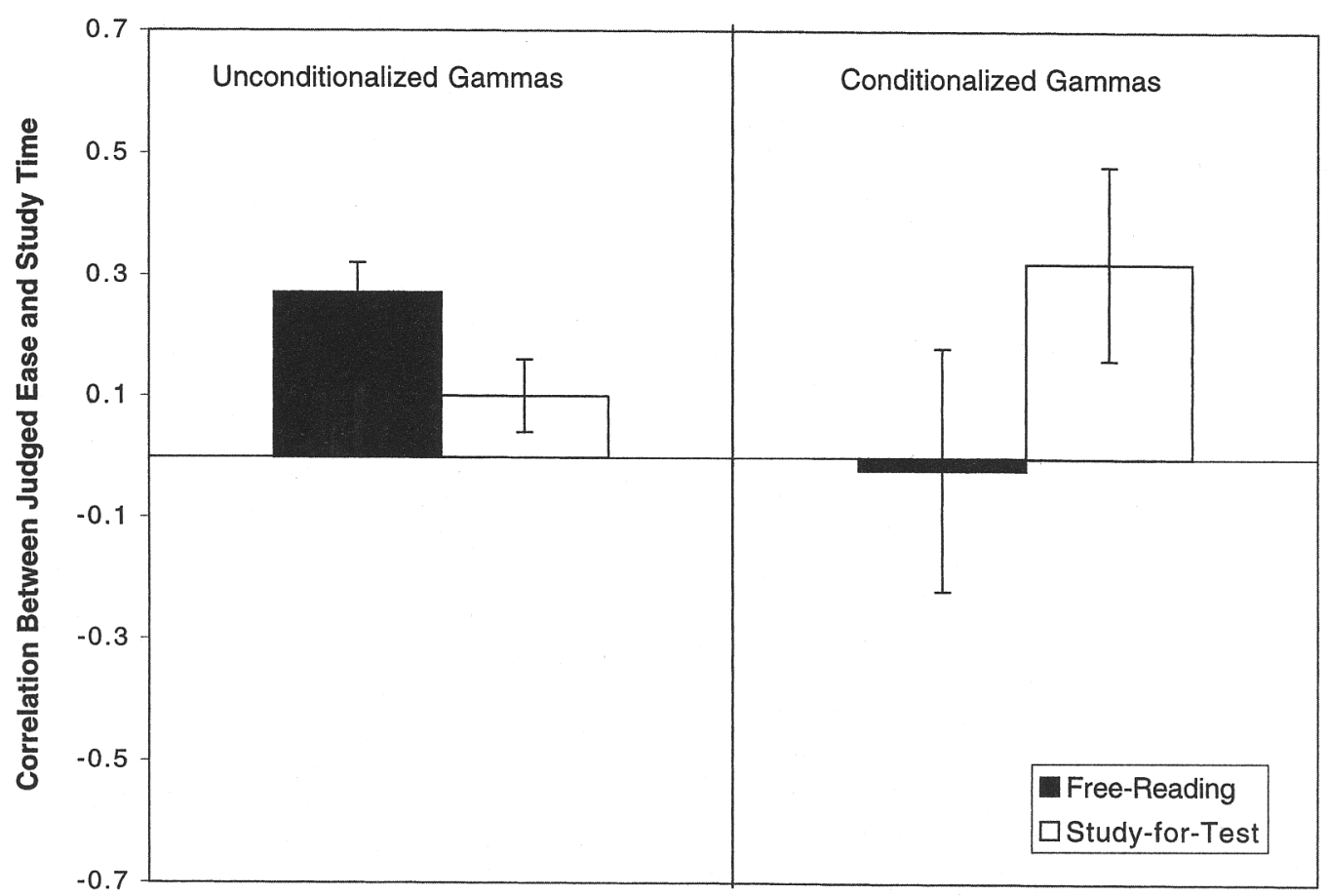

Figure 1. Experiment 1 gamma correlations between ease-of-learning judgments and study time, either unconditionalized or conditionalized on the items that were selected for study.

tionalized scores were 4.40 for the free-reading group and 4.93 for the study-for-test group. The mean conditionalized gamma correlations between EOLs and study time were -.02 for the free-reading group and .37 for the study-for-test group, a nonsignificant difference, $F<1$ (see Figure 1). Because Thiede and Dunlosky's theory assumes that people are studying for a test, we analyzed that condition separately. In contrast to the theory, which predicts a negative correlation, the gamma was significantly greater than zero, $t(15)=$ $2.49, S E=0.15$.

Although our main focus was on study-time allocation, the number of pages that people studied in each biography, not surprisingly, confirmed the already-detailed results: Participants read significantly more pages of biographies (out of a maximum of six pages for each biography) that were judged to be easy rather than difficult in the freereading group, $G=.27$, but not in the study-for-test group, $G=.07$. The two groups were significantly different from each other, $F(1,62)=8.32, M S E=0.56$.

\section{Cognitive Resource Allocation on the Basis of JOIs}

The EOLs and JOIs were significantly correlated, such that the biographies that were judged to be easier also tended to be judged as more interesting, $G=.25, t(62)=5.45$, $S E=0.05$. The mean gamma correlations concerning people's study time as a function of interest (i.e., between JOIs and study time) for the free-reading and study-for-test conditions, respectively, were .32 and .14 , as is shown in Figure 2. Although the difference was not quite significant, $F(1,62)=3.71, M S E=0.48, p=.06$, this trend suggests that when people were free reading, they preferred to devote their time to the judged-interesting materials. However, when studying for a test, although study time was still positively related to interest, it was somewhat less positively so determined. Combined, these gammas were greater than zero, $t(62)=4.84, S E=0.05$. The free-reading group read a greater number of pages of judged-interesting biographies, $G=.34$, than did the study-for-test group, $G=.11, F(1,62)$ $=10.96, M S E=0.80$.

\section{Discussion}

The most important new result in this experiment was that, in contrast to all previous findings, people devoted their study time to items that were assessed as easy rather than difficult. One possible reason for this finding may have been that in our experiment, people had very little overall study time relative to the amount of material given. If the judged-difficult biographies were thought to be too difficult to learn in such a short amount of time, participants may have decided, instead, to spend their study time on the less-difficult biographies that were learnable in a shorter time period. The second reason for the finding may have been that the materials that we used were much more complex and demanding than those simple materials used in past studies. Perhaps the nature of the materials interacts with study-time-allocation strategies. Thus, our concern that the apparently robust finding in the literature-that people study the difficult items longer-may apply under only very specific, but as yet not fully specified special conditions, appears to be justified. Under the conditions used in our 


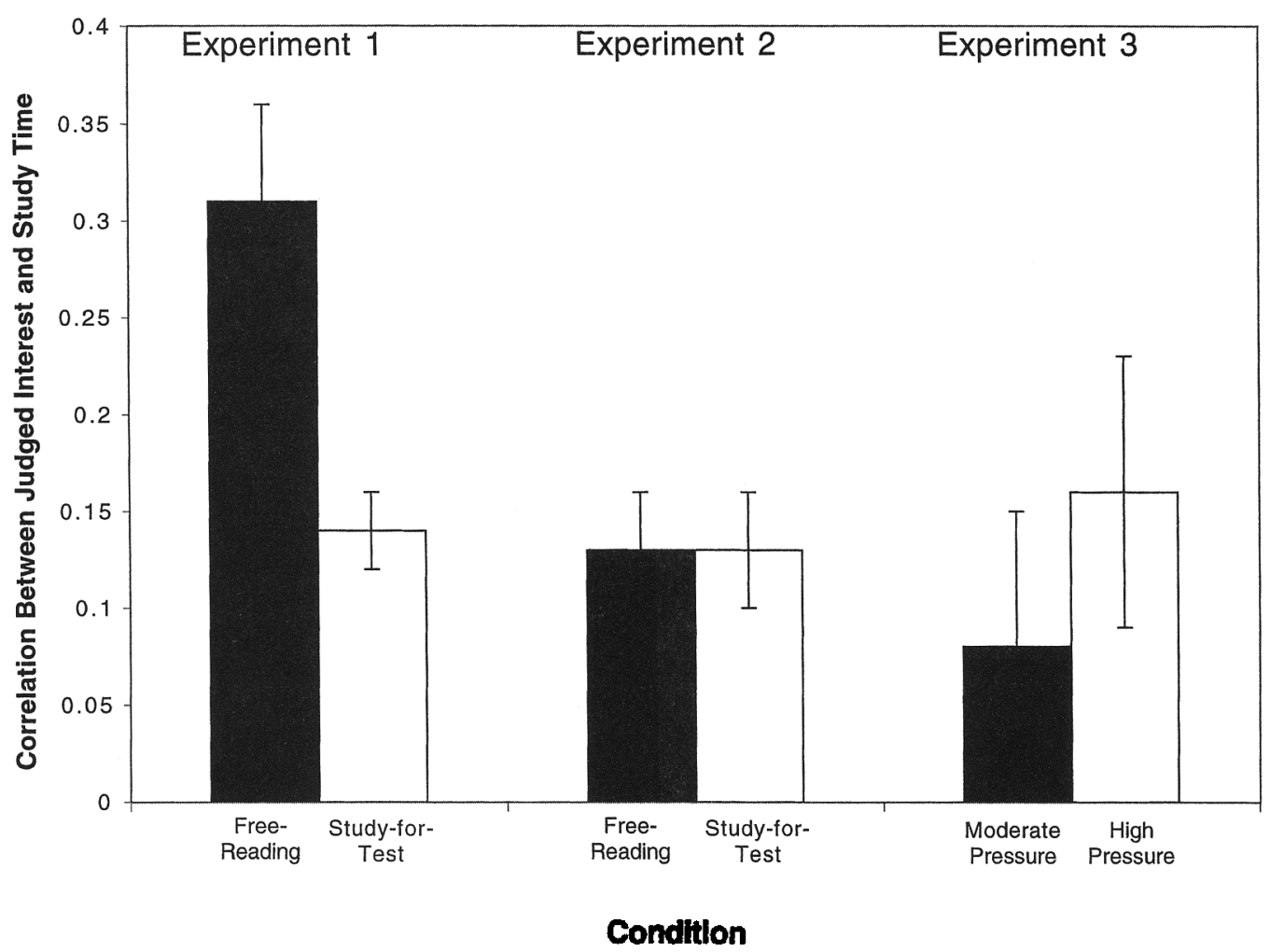

Figure 2. Gamma correlations between judgments of interest and study time. Experiment 1 materials were long biographies; Experiment 2 materials were haikus; Experiment 3 materials were Elizabethan sonnets.

experiment, where the stimulus materials were longer and people had little time, the reverse occurred.

The second finding that emerged was that test expectation influenced people's studying strategy. When people were free reading, they allocated more study time to those biographies judged as easy. However, when a test was expected, they spent less time on the judged-easy biographies than they would have had they not been expecting a test. The difference in study strategy, however, did not improve performance very much. However, had the participants been given more time in which to study, perhaps these strategy differences would have been more effective.

Finally, people's judgments of interest were positively related to study time. This last finding suggests that there may be some hedonic basis for time allocation. People appear to study, not just what they should-as given by the cool assessment of how well the items are learned-but also what they would-as given by the hot judgments of interest. This finding suggests that emotionally guided impulses (see Metcalfe \& Mischel, 1999), such as the person's interest in the materials, may influence control strategies even in a simple learning paradigm.

\section{Experiment 2}

In Experiment 2, we attempted to alter the paradigm in a direction that would produce the more common result in the literature. As noted above, the difference between our results-that people tended to study the judged-easy items longer-and those shown in other experiments-that people tended to study the judged-difficult items longer-might have been caused by the fact that the stimuli used in the two cases were very different. We used long biographies, in Experiment 1, whereas other researchers had used short sentences, word-pairs, trigrams, and even letters. Thus, in the second experiment, we used materials that were closer in length to the word pairs and phrases used in the past. At the same time, we wanted the stimuli to be complex enough so that there would be a wide range of interest judgments. Therefore, we chose haiku poems as our to-be-learned materials.

The other main difference between our first experiment and most of those reported in the literature was that in our experiment, people had very little time to study the materials. In most previous experiments, people have had plenty of time. In an effort to make the second experiment more like those in the literature-while still maintaining the total fixed-time strategic aspect of the first experiment-we calibrated the total time allowed in this experiment to be more than twice as long as was needed to read through all of the materials. In addition, we attempted to replicate the free-reading versus study-for-test difference in strategies found in the first experiment. Thus, we included a similar manipulation in this experiment. 


\section{Method}

\section{Participants}

The participants were 28 undergraduates from the same population as in Experiment 1; none of them had participated in Experiment 1.

\section{Design}

We used a two-group design (test expectation: free-reading vs. study-for-test), in which participants studied 7 haiku poems in each of seven blocks, for a total of 49 haikus. Each haiku was scored out of 10 , and then the scores were converted to proportions. As in Experiment 1, two metacognitive judgments were elicited--EOLs and JOIs. We also measured the study time on each haiku. Participants were assigned randomly to condition.

\section{Materials}

Forty-nine Japanese haiku poems, translated into English, were selected as stimuli for Experiment 2. The poems consisted of a wide variety of topics and abstractness. In a pretest, two graduate students averaged $50 \mathrm{~s}$ to read through 7 haiku poems in a row. Participants were allowed 2 min to study each set of 7 poems.

\section{Procedure}

Within each block, the judgment stage consisted of participants reading 7 different haiku poems for $3 \mathrm{~s}$ each, then rating them (on a scale from 1 to 10 ) in terms of ease-of-learning and interest (a 10 was given for easiest or for most interesting). Then, participants in the study-for-test condition were told that they would have to study the haiku poems for a later test; participants in the free-reading condition were told nothing about a test. The instructions for the study-for-test group were as follows: "You will now have the opportunity to read through and study the 7 haiku poems for $2 \mathrm{~min}$. There will be a memory test on the free recall of all 7 haiku poems, after the $2 \mathrm{~min}$ has ended. You may read the haikus as you wish, choosing each of them for as long as you'd like. You can always go back to one that you've already read, and don't worry if you don't get through all of them." The instructions for the free-reading condition were as follows: "You will now have the opportunity to free-read through the 7 haiku poems for $2 \mathrm{~min}$. You may read the haikus as you wish, choosing each of them for as long as you'd like. You can always go back to one that you've already read, and don't worry if you don't get through all of them."

The study stage immediately followed the instructions. All participants had 2 min to read as many poems as they wished. The 7 poems were presented in a circular array on a computer screen in a very faint light gray color that was extremely hard to read, yet still recognizable. Participants could choose a haiku poem to read more comfortably by clicking on that poem. By doing so, the 6 poems that were not chosen disappeared, whereas the one poem chosen became easily readable. When the participant finished studying a particular poem, he or she could return to the circle of the 7 barely-readable haiku poems by clicking the mouse once again, at which point another poem could be chosen. Time spent on each poem and selection order were recorded by the computer.

After studying the 7 haiku poems for $2 \mathrm{~min}$, participants in the study-for-test condition had to recall the 7 poems as well as they could by writing them on a piece of paper. Thus, they were tested after each of the seven blocks of haikus. In the free-reading condition, only the seventh, or final, block was tested for free recall. We only tested on the final block so that during all the study phases, these participants would continue to have no knowledge that their memory would be tested.

\section{Results}

Recall was scored by two independent judges, both blind to the experimental conditions. Scores ranged from zero, when nothing was recalled, to 10 , for perfect recall of a particular haiku poem. Both judges agreed to give a point for each significant word recalled. However, in addition, the judges gave a subjective score for the full haiku, reflecting the correct flow and theme of the poem. The interjudge correlation was very high, at .95 . The averages of the scores given by the two judges were used as the test performance scores in the analyses.

\section{Test Performance}

Because we only had test scores for the seventh block for the free-reading participants, the analyses that compare the test-expectation conditions on test performance were conducted only on the seventh block. The mean proportion correct on the test for the free-reading and study-for-test groups were .39 and .45 , respectively. A $t$ test showed no significant difference between the two groups in test performance $(t<1)$, but there were very few observations on this measure, so we do not conclude that test expectation did not influence performance.

As is shown in Table 2 (Experiment 2), there was no difference on the correlation between EOLs and test performance (computed only on the last block) between the two test-expectation conditions $(F<1)$. Both were better on haikus judged as easy, $G=.25, t(27)=4.31, S E=0.06$. There was also no difference on the correlation between JOIs and test performance between the two test-expectation conditions $(F<1)$, and interest judgments computed only on the seventh block did not significantly predict test performance in this experiment, $G=.10, t(27)=1.54$, $p=.14$.

There was no difference as a function of test expectations on the gamma correlations between study time and test performance (on the last block). However, there was a difference from zero, such that the more time a person allocated to studying a particular haiku, the better was its recall, $G=.22, t(27)=3.74, S E=0.03$. These results are similar to those of Experiment 1.

We also conducted an analysis of variance (ANOVA) on all 7 blocks in the study-for-test condition, which showed no effect of block. However, a $t$ test showed that people performed better on the judged-easy items, $G=.08, t(97)=$ $2.58, S E=0.03$. Over all blocks, we also found that people performed better on the judged-interesting items, $G=.16$, $t(97)=4.80, S E=0.03$.

\section{Cognitive Resource Allocation on the Basis of EOLs}

Unlike the results of Experiment 1, and like those found in the rest of the literature, in this experiment there was a negative relation between study time and EOL judgments, 
combined $G=-.12, t(197)=3.70, S E=0.03$. The two test-expectation conditions were significantly different from each other, $F(1,26)=5.05, M S E=0.87$. The gammas for the study-for-test group $(G=-.19)$ showed that in this condition, participants allocated more study time to the judged-difficult materials; the gamma was significantly less than zero, $t(97)=6.16, S E=0.03$. The analogous $t$ test comparing the gammas in the free-reading group to zero did not quite reach significance, $G=-.05, t(97)=1.83, S E=$ $0.03, p=.07$. (The Pearson correlation for the free-reading group was -.05 . The Pearson correlation for the study-fortest group was -.08 . The ANOVA on the Pearson correlations showed no effect of test expectation, but the combined correlation showed that people allocated more study time to the judged-difficult haikus, $t[195]=2.05, S E=0.03$.)

Because of the predictions of Thiede and Dunlosky's (1999) theory, we examined the order in which items were selected for study. The gamma correlations between EOLs and selection order showed no differences between groups $(-.02$ for the free-reading group and .04 for the study-fortest group) and were not significantly different from zero, suggesting that there was no specific selection-order strategy. (The Pearson correlations yielded slightly different results: For the free-reading group $r$ was .14 and for the study-for-test group $r$ was -.07 . The two groups were significantly different from each other, $F(1,26)=4.87$, $M S E=1.72$. Only the free-reading group selected the judged-difficult haikus earlier, $t(97)=3.15, S E=0.04$.)

We also conducted a conditionalized analysis on only those haikus that had been selected for study, eliminating the last haiku that people were studying when the time had run out. The mean number of haikus contributing to this analysis was 5.84. There was a trend, $F(1,26)=2.88, M S E=0.67$, $p=.10$, suggesting that the study-for-test group allocated more study time to the judged-difficult haikus than did the free-reading group. The mean gamma for the study-for-test group was significantly less than zero, $G=-.18, t(97)=$ 3.62 , $S E=0.05$, as is consistent with Thiede's and Dunlosky's theory. Both the unconditionalized and conditionalized results are presented in Figure 3.

\section{Cognitive Resource Allocation on the Basis of JOIs}

As was found in Experiment 1, EOLs and JOIs were slightly correlated, such that the haikus that were judged to be easier also tended to be judged as more interesting, $G=$ $.16, t(195)=6.71, S E=0.02$. The mean gamma correlations between JOIs and study time, shown in Figure 2, indicated that both the study-for-test group $(G=.13)$ and the free-reading group $(G=.13)$ allocated more study time to the judged-interesting materials, $t(195)=5.49, S E=$ 0.02 .

\section{Discussion}

In contrast to Experiment 1, the results concerning the relation between study time and judged ease from Experiment 2 indicated that people spent more time studying items that were judged to be difficult than those judged to be easy but only when expecting a test. These results are in keeping with most of the past literature. This result was expected

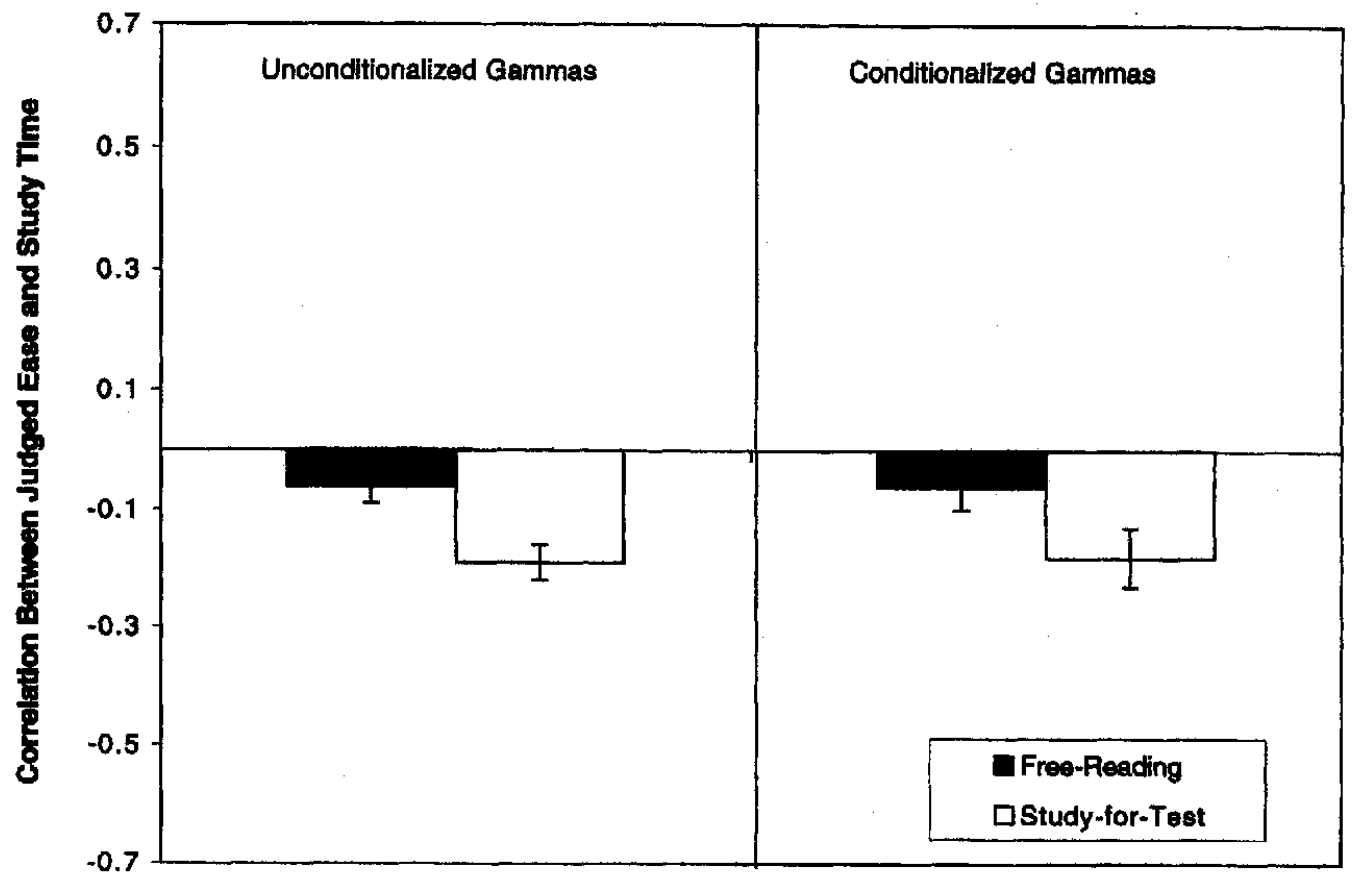

Figure 3. Experiment 2 gamma correlations between ease-of-learning judgments and study time, either unconditionalized or conditionalized on the items that were selected for study. 
because we had tried to manipulate the conditions of the second experiment to be more like those found in the remainder of the literature. The most obvious reason for the discrepancy between the first two experiments was that the stimulus materials were different.

However, another reason may have been that the time pressure during study was different. In Experiment 1, the amount of time needed to read through all eight biographies was approximately twice as long as the amount of study time that was allowed. On the other hand, in Experiment 2, the amount of time needed to read through, though not necessarily to memorize, 7 haiku poems in any given block was only around $50 \mathrm{~s}$. The total study time allowed was $2 \mathrm{~min}$. Put differently, because in Experiment 1, the participants had a very limited period of time to study the biographical information, they may have perceived themselves to be under high time pressure. In Experiment 2, participants could at least read through all the poems. If they knew how long it would take them to master certain items and also that it would take longer to master the judged-difficult items, then they might have allocated more study time to judgeddifficult items only when there was ample study time. On the other hand, when there was not enough study time, they might have allocated more time to items that were judged as easy or those items that would take a shorter amount of time to master.

Thus, we hypothesized that perhaps when there is not enough time to read all the to-be-studied materials, people may be less inclined to study the judged-difficult materials. Given more study time, they may find it feasible to allocate more time to the judged-difficult materials. Our hypothesis, then-tested in the third experiment-was that time pressure may have a substantial influence on study-time allocation.

\section{Experiment 3}

In Experiment 3, we addressed the question of whether time pressure-in the guise of overall study timeinfluences people's study-time allocation. So that some participants would be under high time pressure, and others would be under moderate time pressure, we chose materials that were, in length, between the biographies used in Experiment 1 and the haikus used in Experiment 2. Thus, medium-length sonnets were used as the sole stimulus materials. The sonnets were also complex enough to sustain interest judgments. The amount of overall study time was varied across groups: Some participants were extremely time pressured; others were only moderately time pressured.

\section{Method}

\section{Participants}

The participants were 28 undergraduates from Columbia University; none of them had participated in the previous experiments. Each participant was paid $\$ 10$ for the session.

\section{Design}

We used a two-group design (time pressure: high pressure vs. moderate pressure) in which participants studied eight different sonnets and were subsequently tested on them. Recall of each sonnet was scored out of 10 and converted to proportion of sonnet correct. As before, EOLs, JOIs, and study time were recorded. Participants were assigned randomly to the conditions and were tested individually.

\section{Materials}

Eight 14-line sonnets were chosen as the stimulus materials, and an extra sonnet was used as a pretest stimulus.

\section{Pretest}

The main experiment was preceded by a pretest phase for all participants, designed to calibrate how much time to give participants in the high-pressure and moderate-pressure groups. A pretest sonnet was presented on the computer screen for $1 \mathrm{~min}$. Participants were told to memorize the sonnet to the best of their ability. After the minute was up, they wrote down as much of the sonnet as they could remember. If they had remembered at least $50 \%$ of the sonnet, the pretest session was terminated. If not, they were given another minute to study, after which they had another chance to write down what they had left out on the previous recall trial. When they recalled at least $50 \%$ of the sonnet, the pretest was terminated. Total study time in the experiment was computed as a function of the number of minutes, $t$, the participant had needed to reach the $50 \%$ criterion. If the participant was assigned to the high-pressure group, he or she was given three times as much time (i.e., $3 t$ ) for all eight sonnets in the experiment; if in the moderate-pressure group he or she was assigned 10 times the number of minutes needed in the pretest session (i.e., 10t). All participants were aware of how long they would have to study. There was, of course, a difference in the overall study times for the two groups. The mean overall study time for participants in the moderate-pressure group was $\mathbf{4 1 . 4 3}$ min, and the mean overall study time for participants in the high-pressure group was $11.79 \mathrm{~min}$.

\section{Procedure}

This experiment used the same basic procedure as was used in Experiments 1 and 2. During the judgment stage, participants read and rated eight new sonnets for EOL and for interest, both on a scale from 0 to $10(0=$ most difficult and least interesting, $10=$ easiest and most interesting). Then, each of the participants was given the instructions for the remainder of the experiment. They were told how long they would have to study all of the sonnets and that they would be given a memory test, cued with the first two lines of each sonnet, following the study phase. As in the first two experiments, participants were informed that they could study the sonnets as they wished, they could always go back to a sonnet that had already been chosen, and that they should not worry if they could not get through all eight of the sonnets.

During the study stage, the first two lines of all eight sonnets were displayed in a circular array. When a participant clicked the mouse on any two lines, the entire sonnet was presented on the screen until the participant clicked the mouse again to return to the main array. Again, time spent studying each sonnet, and selection order of sonnets were both computer recorded. Finally, in the recall stage, the participants were cued with the first two lines of the 
sonnets and were asked to write down as much as they could remember of all eight sonnets.

\section{Results}

Performance was scored by two independent judges, both blind to the experimental conditions. A score between 0 and 10 was assigned for each sonnet on the basis of the amount of accurate recall. A 10 was given for perfect recall, and a 0 was given if none of the sonnet had been recalled. Similar to the scoring of haiku poems, the judges gave logical but subjective scores on the basis of the number of vital words recalled and the theme flow recalled. The interjudge correlation was .97. The averages of the scores given by the two judges were used as the test performance scores in the analyses.

\section{Test Performance}

The mean proportions correct for the high-pressure group (.15) and the moderate-pressure group (.28) were significantly different from each other, $F(1,26)=6.59, M S E=$ 0.98 , as expected.

Results of the gamma correlations between judgments and test performance are presented in Table 2 (Experiment 3). The mean gamma correlations between EOLs and test performance were not significantly different for timepressure groups: .22 for the high-pressure group and .19 for the moderate-pressure group, $F<1$. Both groups performed better on the judged-easy sonnets, the combined gamma being significantly different from zero, $t(27)=5.84, S E=$ 0.03 .
The mean gamma correlations between JOIs and test performance were also not significantly different for groups: .17 and .08 for the high-pressure and moderate-pressure groups, respectively, $F(1,27)=1.64, M S E=0.06, p=.21$, but both showed that people tended to perform better on the judged-interesting sonnets; the combined gamma was signifcantly different from zero, $t(27)=3.40, S E=0.04$. All of the above findings were consistent with those of the previous experiments.

The gammas between study time and performance, computed for each individual and hence nonredundant with the study-time manipulation in this experiment, showed that people recalled better those items that they had studied longer, $G=.10, t(27)=2.34, S E=0.04$.

\section{Cognitive Resource Allocation on the Basis of EOLs}

As in Experiment 1, people in this experiment, allocated their time to the judged-easy rather than the judged-difficult sonnets, $G=.16, t(27)=3.16, S E=0.05$. Furthermore, the study strategy changed depending on time pressure. The mean gamma correlations between EOL and study time were .27 and .05 for the high-pressure and moderate-pressure groups, respectively (see Figure 4), and were significantly different from each other, $F(1,26)=5.29, M S E=0.34$. When under high time pressure, people tended to study the judged-easy items for longer, the gamma being significantly different from zero, $t(13)=4.57, S E=0.06$. Those participants who were under only moderate pressure showed no tendency to study preferentially either the judged-easy or the judged-difficult items, and the gamma was not significantly different from zero, $t(13)=0.71, S E=0.08, p>.40$.

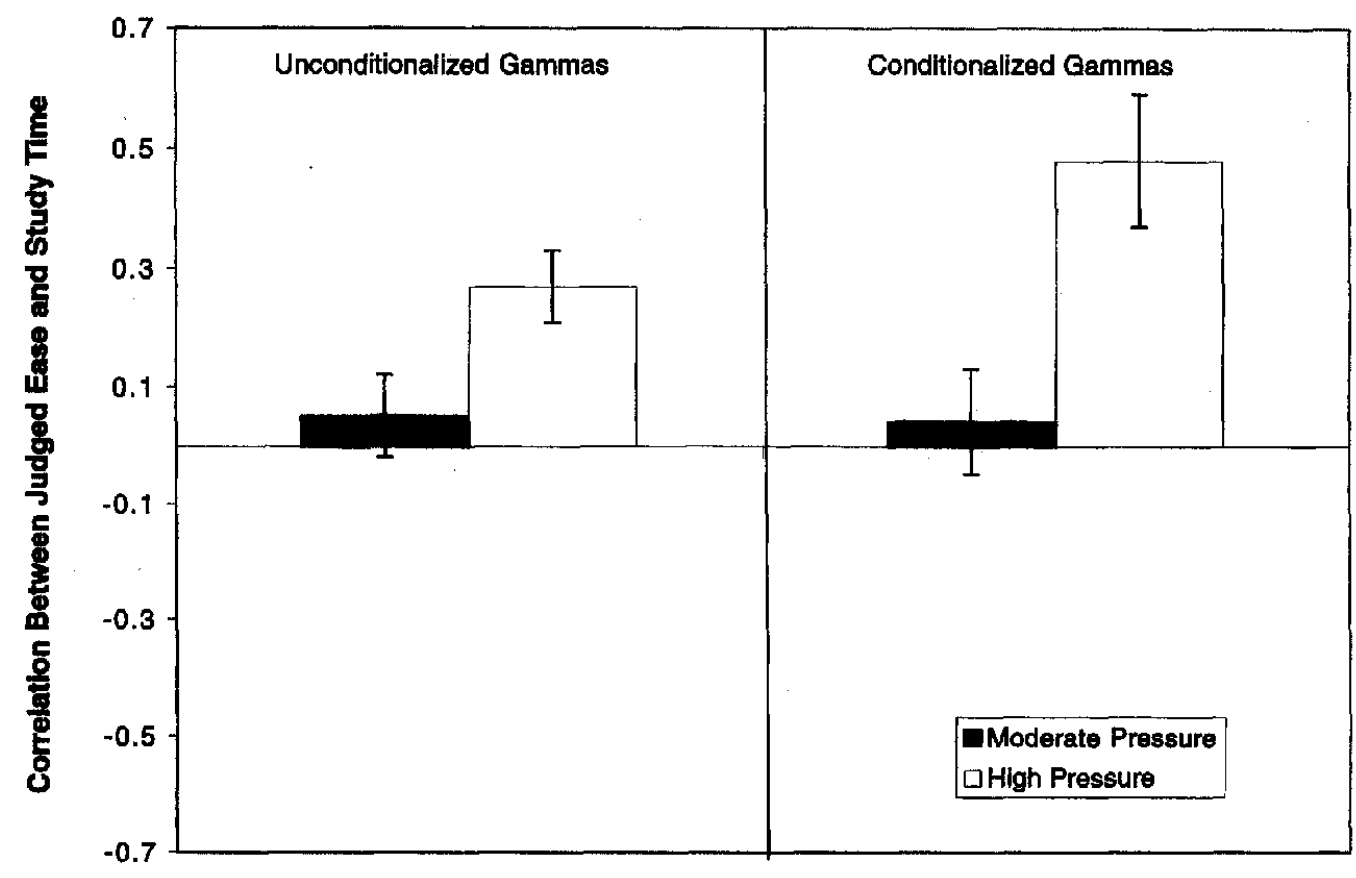

Figure 4. Experiment 3 gamma correlations between ease-of-learning judgments and study time, either unconditionalized or conditionalized on the items that were selected for study. 
We found no change in this pattern when we conditionalized on the chosen sonnets and eliminated the sonnets that the person was studying when time ran out. The mean number of sonnets entering this conditionalized analysis in the high-pressure group was 5.36 and in the moderatepressure group was 7.71. People in the high-pressure group allocated more study time to sonnets judged as easy $(G=.46), t(13)=4.79, S E=.10$, whereas people in the moderate-pressure group did not allocate more time specifically to judged-difficult or easy sonnets $(G=.04)$. Neither of these two results support Thiede's and Dunlosky's theory. As in the unconditionalized analyses, the two group's studying strategies were significantly different from each other, $t(13)=2.93, S E=0.14$. Both the unconditionalized and conditionalized results are shown in Figure 4.

As in the previous experiment, the gamma correlations between EOLs and selection order showed no differences between groups (.13 for the moderate-pressure group and .18 for the high-pressure group). However, the combined mean gamma correlation was significantly greater than zero, $G=.15, t(27)=2.91, S E=0.05$, indicating that people selected the judged-easy haikus earlier.

\section{Cognitive Resource Allocation Based on JOIs}

The judged-easy sonnets were also judged to be more interesting, $G=.24, t(27)=3.81, S E=0.06$. Both groups devoted more study time to the judged-interesting sonnets; the gamma was significantly different from zero, $t(27)=$ $2.30, S E=0.05$, as is shown in Figure 2 .

\section{Discussion}

The results of Experiment 3 suggest an interpretation of the differences we found between Experiments 1 and 2. In Experiment 1, participants may have perceived themselves to be under extremely high time pressure. Under such circumstances, they tended to allocate study time to the judged-easy items. In Experiment 2, though, because they had time to at least read all of the materials, they may have perceived themselves to be under lower time pressure, in which case the usual finding resulted: They preferentially allocated study time to the judged-difficult items. Consistent with this conjecture, in Experiment 3, participants in the high-pressure condition allocated more study time to the judged-easy items, whereas when the time pressure was lessened in the moderate-pressure condition, so too was people's tendency to allocate their time to the judged-easy items.

Although we prefer this interpretation of our results, there is also a possibility that under conditions of low time pressure, people's study strategies become less discriminate and more noisy and hence tend toward a zero correlation. This alternate hypothesis cannot be refuted from our data, and there are two studies (Mazzoni \& Cornoldi, 1993, Experiment 5; Nelson \& Leonesio, 1988) that attained correlations in the opposite direction from ours in the high pressure condition, which reported that under lower time pressure the correlations were closer to zero. Hence, these two studies are consistent with the alternate interpretation of our results, rather than with our preferred interpretation. However, the conditions in these two experiments were quite different from those in Experiment 3. In a fact-learning experiment, Mazzoni and Cornoldi (1993) gave participants either $15 \mathrm{~s}$ per item or $60 \mathrm{~s}$ per item. They found that the high time pressure group preferentially allocated more time to the judged-difficult items than did the low time pressure group, which had a correlation close to zero. Their study differs from ours insofar as they allowed no trade-off across items - the participant had the full amount of time (either 15 $\mathrm{s}$ or $60 \mathrm{~s}$ ) to use on each item and could not allocate the saved time to help performance on other items. Also, the materials were simple statements, and perhaps participants, realizing that they had more time than they could possibly use in the 60-s condition, became unstrategic and inattentive-accounting for the lack of performance differences in the two conditions, despite the differences in study time. Nelson and Leonesio (1988, Experiment 3) found a small difference in study time allocated to each item as a function of instructions that emphasized either speed or accuracy. They found that under the speeded (high pressure) conditions, people showed a greater tendency to allocate time to the more difficult items than they did under the less time-pressured accuracy conditions, in which the correlation tended to zero. However, again, they were not investigating a situation in which time saved on one item could be used, strategically, on another. The overall time frame was also much shorter than that in our studies. The materials were one-sentence fact questions, to which a one-word answer was to be learned. Finally, the direction of the strategic study-time allocation shown in the high-pressure condition was opposite to that in our high-pressure condition.

In our experiment, people under time pressure allocated their study time to the easy items, not those that were perceived to be difficult. They did this less, though, when they had more time, overall, to study. Presumably their reason for this choice of strategy was that they wanted to consolidate those items that, with the least effort, they would be relatively sure of having mastered for the test. It was probably the easy items that required some, but not much, effort to master that would provide the highest payoff at the smallest cost, in terms of test performance. This strategy, then, would allow people to optimize test performance, given the amount of study time allowed. In summary, then, people may have realized that there were diminishing returns per unit study time as a function of the difficulty of the items being studied. Thus, under pressure, they chose the easy pickings.

\section{General Discussion}

The most important new finding in the three experiments presented here was that people do not always allocate their study time to items that are judged as difficult; they sometimes devote their time to the items judged to be easy. This result contradicts the results of all 46 previous experi- 
mental conditions in the literature, 35 of which indicate that people study judged-difficult items preferentially, and 11 of which are indeterminate. Furthermore, it disconfirms all existing models of study-time allocation (Dunlosky \& Hertzog, 1998; Nelson \& Narens, 1990, 1994; Thiede \& Dunlosky, 1999), particularly the well-accepted discrepancyreduction model, which states that people will preferentially study what they find most difficult or most uniearned. Like Thiede and Dunlosky (1999), we sometimes found that people chose to study the easier items earlier, but, unlike Thiede and Dunlosky, we found that even when we only considered those items that people chose to study, people still tended, in some situations, to devote more study time to the easy items. Although the addition of a high-level selection process was evoked to reconcile Thiede and Dunlosky's data with the discrepancy-reduction models, it is insufficient to account for our results. Our data are irreconcilable with the models; people seem to use the discrepancyreduction mechanism only under particular very circumscribed conditions.

We are not suggesting that people do not use their metacognitive knowledge to control learning. Our data were systematic, indicating that people were behaving strategically. They were just not systematic in the direction shown by previous research. Our results, then, suggest that people may use their metaknowledge in a rather different and perhaps more strategic way than past research would suggest.

First, time pressure appears to be a factor in deciding which items to study. It was shown here that when under high time pressure, people allocated more study time to the judged-easy items, whereas when under lower time pressure, they turned more to the judged-difficult items. Although the finding that people, sometimes, devote their study time to the easy items contradicts the predictions made by current discrepancy-reduction models, the variation with time pressure, in and of itself, does not conflict with the central intuition of the theory, namely, that it takes more time to learn the difficult items. Indeed, the result suggests that people know this very well and realize that because it takes more time to learn the difficult items, there may be situations in which time spent on those items would be wasted or inefficient. With a severely restricted amount of time available, they should concentrate on those iterns that are expected to have the highest payoff in terms of test performance and the smallest cost in terms of time spent.

Second, study-time allocation was influenced by learning goals. In both experiments, we can compare the correlations when people were studying for a test to when they were free reading. In both experiments, the difference between conditions was in the direction favoring the easier items when they were free reading and the more difficult items when they were studying for a test, regardless of the overall level of the correlations. So, in Experiment 1, the correlation between EOLs and study time was positive for the freereading group and less positive for the study-for-test group. In Experiment 2, the correlation was approximately zero when free-reading and negative when studying for a test. This suggests that when free-reading, people prefer the easier items, but when studying for a test, they sacrifice this preference and attend more to the difficult items.

Finally, we found that EOLs were not the only factor influencing study-time allocation; people also studied according to their interest. In all three experiments, people chose to allocate more study time to materials judged as interesting. And, in general, people performed better on the judgedinteresting materials. Hot-system motivational factors (Metcalfe \& Mischel, 1999) such as interest value have often been ignored in cognitive studies of learning (cf. Berlyne, 1978), but it seems clear that in the real world, as well as in our experiments, they may have a potent, but as yet poorly charted, effect.

The results of these experiments indicate that past theories about the manner in which people allocate their study time are too simple. Because these are the first studies to show that the consensus of past literature is limited to certain very circumscribed conditions, there are necessarily a number of unresolved questions that will need to be intensively and systematically investigated before all of the implications of this line of research are understood. Research on the effects and boundary conditions of each of the parameters that we investigated need to be detailed. It also seems likely that other important determinants of strategic study-timeallocation may wait undiscovered. Until parametric investigations of these variables, under different circumstances of learning and under different motivational sets, have been conducted, it would be premature to suggest a formal theory. However, what these data do suggest is that people may use their metacognitions in a much more strategic and situationsensitive manner than was previously known. Clearly, given the importance of people's metacognitively guided strategies in allowing them to take control over their own learning, these new results deserve intensive follow-up.

\section{References}

Anderson, R. C. (1982). Allocation of attention during reading. In A. Flammer \& W. Kintsch (Eds.), Discourse processing (pp. 292-305). New York: North Holland.

Arbuckle, T. Y., \& Cuddy, L. L. (1969). Discrimination of item strength at time of presentation. Journal of Experimental Psychology, 81, 126-131.

Asher, S. R. (1979). Influence of topic interest on Black children's and White children's reading comprehension. Child Development, 50, 686-690.

Asher, S. R. (1980). Topic interest and children's reading comprehension. In R. Spiro, B. Bruce, \& W. Brewer (Eds.), Theoretical issues in reading comprehension (pp. 525-534). Hillsdale, NJ: Erlbaum.

Asher, S. R., Hymel, S., \& Wigfield, A. (1978). Influence of topic interest on children's reading comprehension. Journal of Reading Behavior, 10, 35-47.

Asher, S. R., \& Markell, R. A. (1974). Sex differences in comprehension of high- and low-interest reading material. Journal of Educational Psychology, 66, 680-687.

Atkinson, R. C. (1972). Optimizing the learning of a secondlanguage vocabulary. Journal of Experimental Psychology, 96, 124-129.

Belmont, J. M., \& Butterfield, E. C. (1971). Learning strategies as 
determinants of memory deficiencies. Cognitive Psychology, 2, 411-420.

Berlyne, D. E. (1978). Curiosity and learning. Motivation and Emotion, 2, 97-175.

Bisanz, G. L., Vesonder, G. T., \& Voss, J. F. (1978). Knowledge of one's own responding and the relation of such knowledge to learning: A developmental study. Journal of Experimental Child Psychology, 25, 116-128.

Brown, A. L. (1978). Knowing when, where, and how to remember: A problem of metacognition. In R. Glaser (Ed.), Advances in instructional psychology (Vol. 1, pp. 77-165). Hillsdale, NJ: Erlbaum.

Craik, F. I. M., \& Tulving, E. (1975). Depth of processing and the retention of words in episodic memory. Jourmal of Experimental Psychology: General, 104, 268-294.

Craik, F. I. M., \& Watkins, M. J. (1973). The role of rehearsal in short-term memory. Journal of Verbal Learning and Verbal Behavior, 12, 599-607.

Cull, W. L., \& Zechmeister, E. B. (1994). The learning ability paradox in adult metamemory research: Where are the metamemory differences between good and poor learners? Memory \& Cognition, 22, 249-257.

Dufresne, A., \& Kobasigawa, A. (1988). Developmental differences in children's spontaneous allocation of study time. The Journal of Genetic Psychology, 149, 87-92.

Dufresne, A., \& Kobasigawa, A. (1989). Children's spontaneous allocation of study time: Differential and sufficient aspects. Journal of Experimental Child Psychology, 47, 274-296.

Dunlosky, J., \& Connor, L. T. (1997). Age differences in the allocation of study time account for age differences in memory performance. Memory \& Cognition, 25, 691-700.

Dunlosky, J., \& Hertzog, C. (1997). Older and younger adults use a functionally identical algorithm to select items for restudy during multitrial learning. Journal of Gerontology: Psychological Science, 52, 178-186.

Dunlosky, J., \& Hertzog, C. (1998). Training programs to improve learning in later adulthood: Helping older adults educate themselves. In D. J. Hacker, J. Dunlosky, \& A. C. Graesser (Eds.), Metacognition in educational theory and practice (pp. 249276). Mahwah, NJ: Erlbaum.

Dunlosky, J., \& Nelson, T. O. (1992). Importance of the kind of cue for judgments of learning (JOL) and the delayed-JOL effect. Memory \& Cognition, 20, 374-380.

Dunlosky, J., \& Nelson, T. O. (1994). Does the sensitivity of judgments of learning (JOLs) to the effects of various study activities depend on when the JOLs occur? Journal of Memory and Language, 33, 545-565.

Dunlosky, J., \& Nelson, T. O. (1997). Similarity between the cue for judgments of learning (JOL) and the cue for test is not the primary determinant of JOL accuracy. Journal of Memory and Language, 36, 34-49.

Dweck, C. S. (1996). Capturing the dynamic nature of personality. Joumal of Research in Personality, 30, 348-362.

Flavell, J. H. (1979). Metacognitive and cognitive monitoring: A new area of cognitive developmental inquiry. American Psychologist, 34, 906-911.

Flavell, J. H., \& Wellman, H. M. (1977). Metamemory. In R. V. Kail \& J. W. Hagen (Eds.), Perspectives on the development of memory and cognition (pp. 3-33). Hillsdale, NJ: Erlbaum.

Gardiner, J. M., \& Klee, H. (1976). Memory for remembered events: An assessment of output monitoring in free recall. Journal of Verbal Learning and Verbal Behavior, 15, 227-234.

Gollwitzer, P. M., \& Moskowitz, G. B. (1996). Goal effects on action and cognition. In E. T. Higgins \& A. W. Kruglanski (Eds.),
Social psychology: Handbook of basic principles (pp. 361-399). New York: Guilford Press.

Grant, H., \& Dweck, C. S. (1999). A goal analysis of personality and personality coherence. In D. Cervone \& Y. Shoda (Eds.), The coherence of personality (pp. 341-371). New York: Guilford Press.

Groninger, L. D. (1979). Predicting recall: The feeling-that-I-willknow phenomenon. American Journal of Psychology, 92, 45-58.

Gruneberg, M. M., \& Monks, J. (1974). "Feeling of knowing" and cued recall. Acta Psychologica, 38, 257-265.

Hart, J. T. (1965). Memory and the feeling-of-knowing experience. Journal of Educational Psychology, 56, 208-216.

Hyde, T. (1973). Differential effects of effort and type of orienting task on recall and organization of highly associated words. Journal of Experimental Psychology, 97, 111-113.

Hyde, T. S., \& Jenkins, J. J. (1969). The differential effects of incidental tasks on the organization of recall of a list of highly associated words. Journal of Experimental Psychology, 82, $472-481$.

Hyde, T. S., \& Jenkins, J. J. (1973). Recall for words as a function of semantic, graphic, and syntactic orienting tasks. Journal of Verbal Learning and Verbal Behavior, 12, 471-480.

Jacoby, L. L., Bjork, R. A., \& Kelley, C. M. (1993). Illusions of comprehension and competence. In D. Druckman \& R. A. Bjork (Eds.), Learning, remembering, believing: Enhancing team and individual performance (pp. 57-80). Washington, DC: National Academy Press.

Johnson, M. K. (1988), Reality monitoring: An experimental phenomenological approach. Journal of Experimental Psychology: General, 117, 390-394.

Johnson, M. K., \& Raye, C. L. (1981). Reality monitoring. Psychological Review, 88, 67-85.

Johnston, C. D., \& Jenkins, J. J. (1971). Two more incidental tasks that differentially affect associative clustering in recall. Joumal of Experimental Psychology, 89, 92-95.

Kausler, D. H., Laughlin, P. R., \& Trapp, E. P. (1963). The effects of incentive-set on relevant and irrelevant (incidental) learning in children. Child Development, 34, 195-199.

Kausler, D. H., \& Trapp, E. P. (1962). Effects of incentive-set and task variables on relevant and irrelevant learning in serial verbal learning. Psychological Reports, 10, 451-457.

Kellas, G., \& Butterfield, E. C. (1971). Effect of response requirement and type of material on acquisition and retention performance in short-term memory. Journal of Experimental Psychology, 88, 50-56.

King, J. F., Zechmeister, E. B., \& Shaughnessy, J. J. (1980). Judgments of knowing: The influence of retrieval practice. American Journal of Psychology, 93, 329-343.

Kobasigawa, A., \& Dufresne, A. (1992). Differential allocation of study time by grade 3 children. Unpublished manuscript.

Kobasigawa, A., \& Metcalf-Haggert, A. (1993). Spontaneous allocation of study time by first- and third-grade children in a simple memory task. The Journal of Genetic Psychology, 154, 223-235.

Koriat, A. (1975). Phonetic symbolism and feeling of knowing. Memory \& Cognition, 3, 545-548.

Koriat, A. (1993). How do we know what we know? The accessibility model of the feeling of knowing. Psychological Review, 100, 609-639.

Koriat, A. (1995). Dissociating knowing and the feeling of knowing: Further evidence for the accessibility model. Journal of Experimental Psychology: General, 124, 311-333.

Koriat, A. (1997). Monitoring one's own knowledge during study: A cue-utilization approach to judgments of learning. Journal of Experimental Psychology: General, 126, 349-370.

Koriat, A. (1998). Metamemory: The feeling of knowing and its 
vagaries. In M. Sabourin \& F. I. M. Craik (Eds.), Advances in psychological science, Vol. 2: Biological and cognitive aspects (pp. 461-479). Hove, England: Psychology Press.

Koriat, A., \& Goldsmith, M. (1996). Monitoring and control processes in the strategic regulation of memory accuracy. Psychological Review, 103, 490-517.

Koriat, A., \& Goldsmith, M. (1998). The role of metacognitive processes in the regulation of memory performance. In $G$. Mazzoni and T. O. Nelson (Eds.), Metacognition and cognitive neuropsychology: Monitoring and control processes (pp. 97118). Mahwah, NJ: Erlbaum.

Le Ny, J. F., Denhiere, G., \& Le Taillanter, D. (1972). Regulation of study-time and interstimulus similarity in self-paced learning conditions. Acta Psychologica, 36, 280-289.

Leonesio, R. J., \& Nelson, T. O. (1990). Do different metamemory judgments tap the same underlying aspects of memory? Journal of Experimental Psychology: Learning, Memory, and Cognition, $16,464-470$.

Lovelace, E. A. (1984). Metamemory: Monitoring future recallability during study. Journal of Experimental Psychology: Learning, Memory, and Cognition, 10, 756-766.

Masur, E. F., McIntyre, C. W., \& Flavell, J. H. (1973). Developmental changes in apportionment of study time among items in a multitrial free recall task. Journal of Experimental Child Psychology, 15, 237-246.

Mazzoni, G., \& Cornoldi, C. (1993). Strategies in study-time allocation: Why is study time sometimes not effective? Journal of Experimental Psychology: General, 122, 47-60.

Mazzoni, G., Cornoldi, C., \& Marchitelli, G. (1990). Do memorability ratings affect study-time allocation? Memory \& Cognition, 18, 196-204.

Mazzoni, G., Comoldi, C., Tomat, L., \& Vecchi, T. (1997). Remembering the grocery shopping list: A study on metacognitive biases. Applied Cognitive Psychology, 11, 253-267.

Mazzoni, G., \& Nelson, T. O. (1995). Judgments of learning are affected by the kind of encoding in ways that cannot be attributed to the level of recall. Journal of Experimental Psychology: Learning, Memory, and Cognition, 21, 1263-1274.

McDaniel, M. A., Blischak, D. M., \& Challis, B. (1994). The effects of test expectancy on processing and memory of prose. Contemporary Educational Psychology, 19, 230-248.

Metcalfe, J. (1986a). Premonitions of insight predict impending error. Journal of Experimental Psychology: Learning, Memory, and Cognition, 12, 623-634.

Metcalfe, J. (1986b). Feeling of knowing in memory and problem solving. Journal of Experimental Psychology: Learning, Memory, and Cognition, 12, 288-294.

Metcalfe, J. (1993). Novelty monitoring, metacognition, and control in a composite holographic associative recall model: Implications for Korsakoff amnesia. Psychological Review, 100, 3-22.

Metcalfe, J. (1996). Metacognitive processes. In E. L. Bjork \& R. A. Bjork, (Eds.), The handbook of peneption and cognition: Memory (Vol. 10, pp. 383-411). San Diego: Academic Press.

Metcalfe, J. (in press). Metamemory: Theory and data. In E. Tulving \& F. I. M. Craik (Eds.), Oxford handbook of memory. Cambridge: Oxford University Press.

Metcalfe, J., \& Mischel, W. (1999). A hot/cool-system analysis of delay of gratification: Dynamics of willpower. Psychological Review, 106, 3-19.

Metcalfe, J., Schwartz, B. L., \& Joaquim, S. G. (1993). The cue-familiarity heuristic in metacognition. Joumal of Experimental Psychology: Learning, Memory, and Cognition, 19, 851-864.

Metcalfe, J., \& Weibe, D. (1987). Intuition in insight and noninsight problem solving. Memory \& Cognition, 15, 238-246.
Nelson, T. O. (1984). A comparison of current measures of the accuracy of feeling-of-knowing predictions. Psychological Bulletin, 95, 109-133.

Nelson, T. O. (1988). Predictive accuracy of the feeling of knowing across different criterion tasks and across different subject populations and individuals. In M. M. Gruneberg, P. E. Morris, \& R. N. Sykes (Eds.), Practical aspects of memory: Current research and issues (pp. 190-196). Chichester, England: Wiley.

Nelson, T. O., \& Dunlosky, J. (1991). When people's judgments of learning (JOL) are extremely accurate at predicting subsequent recall: The delayed-JOL effect. Psychological Science, 2, 267270.

Nelson, T. O., \& Dunlosky, J. (1992). How shall we explain the delayed-judgment-of-learning effect? Psychological Science, 3, 317-318.

Nelson, T. O., Dunlosky, J., Graf, A., \& Narens, L. (1994). Utilization of metacognitive judgments in the allocation of study during multitrial learning. Psychological Science, 5, 207-213.

Nelson, T. O., \& Leonesio, R. J. (1988). Allocation of self-paced study time and the "labor-in-vain effect." Joumal of Experimental Psychology: Learning, Memory, and Cognition, 14, 676-686.

Nelson, T. O., Leonesio, R. J., Landwehr, R. S., \& Narens, L. (1986). A comparison of three predictors of an individual's memory performance: The individual's feeling of knowing versus the normative feeling of knowing versus base-rate item difficulty. Journal of Experimental Psychology: Learning, Memory, and Cognition, 12, 279-287.

Nelson, T. O., Leonesio, R. J., Shimamura, A. P., Landwehr, R. S., \& Narens, L. (1982). Overlearning and the feeling of knowing. Journal of Experimental Psychology: Learning, Memory, and Cognition, 8, 279--288.

Nelson, T. O., \& Narens, L. (1990). Metamemory: A theoretical framework and new findings. In G. H. Bower (Ed.), The psychology of learning and motivation (Vol. 26, pp. 125-141). New York: Academic Press.

Nelson, T. O., \& Narens, L. (1994). Why investigate metacognition? In J. Metcalfe \& A. P. Shimamura (Eds.), Metacognition. Knowing about knowing (pp. 1-25). Cambridge, MA: MIT Press.

Postman, L. (1964). Short-term memory and incidental learning. In A. W. Melton (Ed.), Categories of hwman learning (pp. 146201). New York: Academic Press.

Reder, L. M. (1987). Strategy selection in question answering Cognitive Psychology, 19, 90-138.

Reder, L. M., \& Ritter, F. E. (1992). What determines initial feeling of knowing? Familiarity with question terms, not with the answer. Journal of Experimental Psychology: Leaming, Memory, and Cognition, 18, 435-451.

Schwartz, B. L., \& Metcalfe, J. (1994). Methodological problems and pitfalls in the study of human metacognition. In J. Metcalfe, \& A. P. Shimamura (Eds.), Metacognition: Knowing about knowing (pp. 93-113). Cambridge, MA: MIT Press.

Schwartz, B. L., \& Smith, S. M. (1997). The retrieval of related information influences tip-of-the-tongue states. Journal of Memory and Language, 36, 68-86.

Shirey, L. L., \& Reynolds, R. E. (1988). Effect of interest on attention and learning. Journal of Educational Psychology, 80, $159-166$.

Simon, H. A., \& Newell, A. (1971). Human problem solving: The state of the theory in 1970. American Psychologist, 26, 145-159.

Smith, S. M., Brown, J. M., \& Balfour, S. P. (1991). TOTimals: A controlled experimental method for studying tip-of-the-tongue states. Bulletin of the Psychonomic Society, 29, 445-447.

Thiede, K. W. (1996). The relative importance of anticipated test 
format and anticipated test difficulty on performance. Quarterly Joumal of Experimental Psychology, 49, 901-918.

Thiede, K. W., \& Dunlosky, J. (1994). Delaying students' metacognitive monitoring improves their accuracy in predicting their recognition performance. Joumal of Educational Psychology, $86,290-302$.

Thiede, K. W., \& Dunlosky, J. (1999). Toward a general model of self-regulated study: an analysis of selection of items for study and self-paced study time. Journal of Experimental Psychology: Leaming, Memory, and Cognition, 25, 1024-1037.

Till, R. E., \& Jenkins, J. J. (1973). The effects of cued orienting tasks on the free recall of words. Journal of Verbal Learning and Verbal Behavior, 12, 489-498.

Underwood, B. J. (1966). Individual and group predictions of item difficulty for free-recall learning. Journal of Experimental Psychology, 71, 673-679.

Vesonder, G., \& Voss, J. (1985). On the ability to predict one's own responses while learning. Journal of Memory and Language, 24, 363-376.

Walsh, D. A., \& Jenkins, J. J. (1973). Effects of orienting tasks in free recall in incidental learning: "Difficulty," "effort," and "process" explanations. Journal of Verbal Leaming and Verbal Behavior, 12, 481-488.

Widner, R. L., \& Smith, S. M. (1996). Feeling-of-knowing judgments from the subject's perspective. American Journal of Psychology, 109, 373-387.

Widner, R. L., Smith, S. M., \& Graziano, W. G. (1996). The effects of demand characteristics on the reporting of tip-of-the-tongue and feeling-of-knowing states. American Journal of Psychology, 109, 525-538.

Wolk, S. (1974). The influence of meaningfulness upon intentional and incidental learning of verbal material. Memory \& Cognition, 2, 189-193.

Zacks, R. T. (1969). Invariance of total learning time under different conditions of practice. Joumal of Experimental Psychology, 82, 441-447.
Received November 23, 1998 Revision received July 14, 1999 Accepted August 4, 1999 